\title{
Temporal variability in foraminiferal morphology and geochemistry at the West Antarctic Peninsula: a sediment trap study
}

Anna Mikis ${ }^{1}$, Katharine R. Hendry ${ }^{2}$, Jennifer Pike ${ }^{1}$, Daniela N. Schmidt ${ }^{2}$, Kirsty M. Edgar ${ }^{2,3}$, Victoria Peck ${ }^{4}$, Frank J.C. Peeters ${ }^{5}$, Melanie J. Leng ${ }^{6}$, Michael P. Meredith ${ }^{4}$, Chloe L. Todd ${ }^{2}$, Sharon Stammerjohn ${ }^{7}$, and Hugh Ducklow ${ }^{8}$

${ }^{1}$ School of Earth and Ocean Sciences, Cardiff University, Main Building, Cardiff, CF10 3AT, UK

${ }^{2}$ School of Earth Sciences, University of Bristol, Wills Memorial Building, Queen's Road, Bristol, BS8 1RJ, UK

${ }^{3}$ now at School of Geography, Earth and Environmental Sciences, University of Birmingham, Edgbaston, Birmingham, B15 2TT, UK

${ }^{4}$ British Antarctic Survey, High Cross, Madingley Road, Cambridge, CB3 0ET, UK

${ }^{5}$ Department of Earth Sciences, Faculty of Sciences, Vrije Universiteit Amsterdam, De Boelelaan 1085, 1081 HV, Amsterdam, The Netherlands

${ }^{6}$ NERC Isotope Geosciences Facilities, British Geological Survey, Keyworth, Nottingham, NG12 5GG, UK and Centre for Environmental Geochemistry, School of Biosciences, Sutton Bonington Campus, University of Nottingham, Loughborough, LE12 5RD, UK

${ }^{7}$ Institute of Arctic and Alpine Research, University of Colorado Boulder, Boulder, CO 80303, USA

${ }^{8}$ Lamont-Doherty Earth Observatory, Columbia University, 61 Route 9W, Palisades, NY 10964-1000 USA

\section{Supplementary Information}




\section{Weekly averages of sediment trap data}

All foraminifera specimens were removed from the sediment trap cups, and counted. The data presented in the main text represent number of specimens per $\mathrm{m}^{2}$ per day, averaged to a one day period. To account for the production and settling time the flux records were shifted by one week based on Nps sinking speeds of 0.189 to $0.431 \mathrm{~cm} / \mathrm{s}$ reported by Von Gyldenfeldt et al. (2000). The time-shifted Nps flux and stable isotope records were used to create average annual composite figures (Figures S1 and S2) following methods used by Jonkers et al. (2010). 


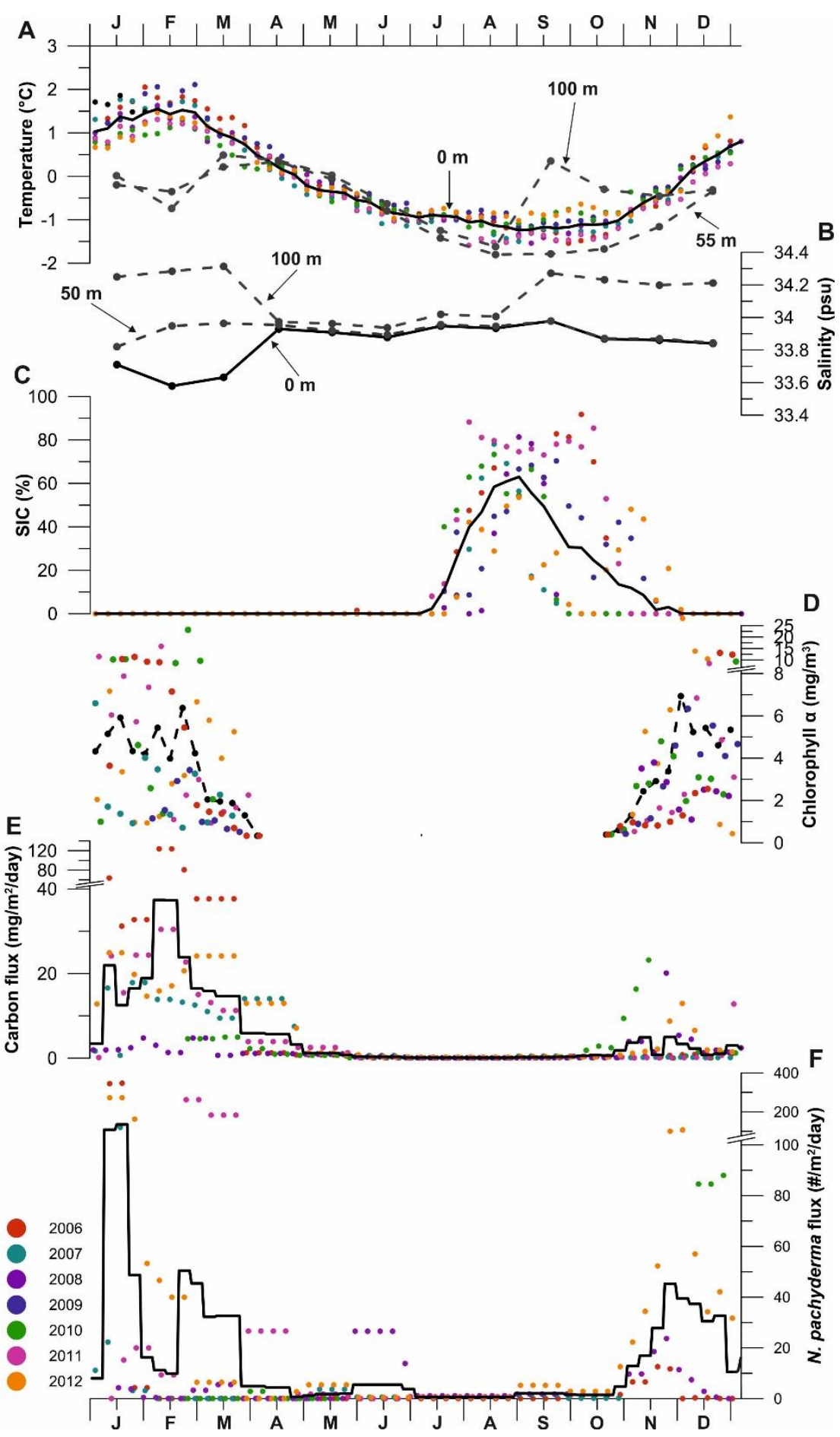

Figure S1: Weekly averaged and time-shifted time series flux record (solid lines: average values of 2006-2012 period; coloured dots are individual years). A) Annual satellite-derived weekly SST (black line) and WOA13 monthly temperature at $55 \mathrm{~m}$ and $100 \mathrm{~m}$ water depths (grey lines). B) WO13 monthly salinity record at surface (black line), 50 and $100 \mathrm{~m}$ (grey lines). C) Annual satellite-derived daily sea-ice concentration. D) Average chlorophyll $a$ concentration $(10-20 \mathrm{~m})$, E) Average organic carbon flux. F) Nps flux record (extremely high flux of 2010 removed from calculation). The low fluxes of early January and sudden drop-off at the end of December are due to gaps in the sampling period. 


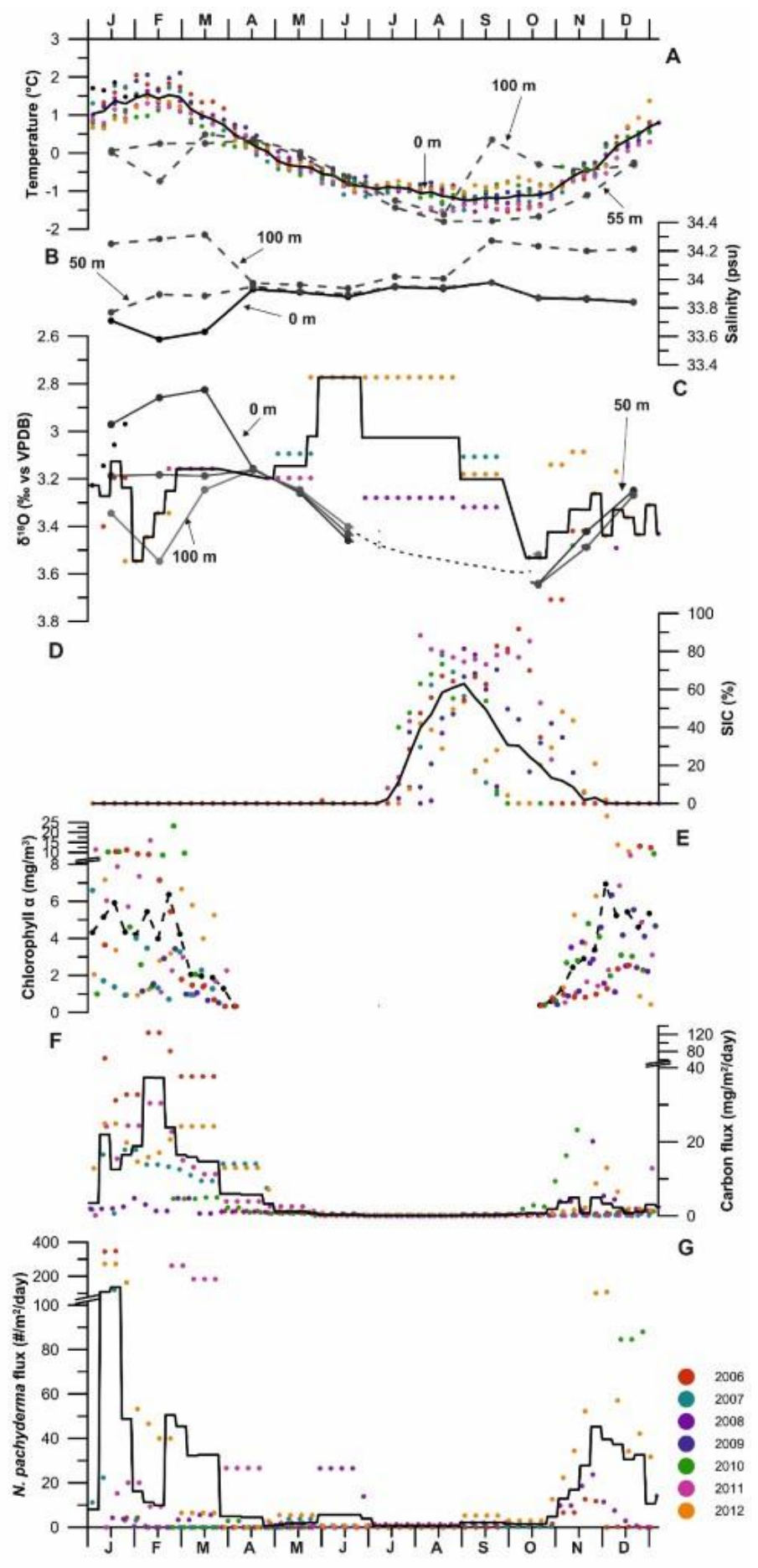

Figure S2: Weekly averaged and time-shifted time series $\square^{18} \mathrm{O}_{\mathrm{np}}$ record (solid lines: average values of 2006-2012 period; coloured dots are individual years). A) Annual satellite-derived weekly SST (black line) and WOA13 monthly temperature at $55 \mathrm{~m}$ and $100 \mathrm{~m}$ water depths (grey lines). B) WO13 monthly salinity record at surface (black line), 50 and $100 \mathrm{~m}$ (grey lines). C) Multi-specimen $\delta^{18} \mathrm{O}^{\mathrm{np}}$ record, $\delta^{18} \mathrm{O}_{\mathrm{eq}}$ at surface, 50 and $100 \mathrm{~m}$ water depths. D) Annual satellite-derived daily sea-ice concentration. E) Average chlorophyll $a$ concentration (10-20 m), F) Average organic carbon flux. G) Nps flux record (extremely high flux of 2010 removed from calculation). 
Table S1: Nps flux statistics summary

\begin{tabular}{|c|c|}
\hline Mean & 286.76 \\
\hline Median & 3.68 \\
\hline Standard deviation & 1392.73 \\
\hline Variance & 1939695.83 \\
\hline Minimum & 0 \\
\hline Maximum & 9586.29 \\
\hline Mean $+1 \sigma$ & 1679.49 \\
\hline Mean $+2 \sigma$ & 3072.22 \\
\hline Quartile 1 & 0 \\
\hline Quartile 2 & 3.68 \\
\hline Quartile 3 & 23.7 \\
\hline Top outliers $(Q 3+(1.5 x I Q R))$ & $>59.3$ \\
\hline
\end{tabular}


2. Anderson-Darling tests for normality of morphometric data
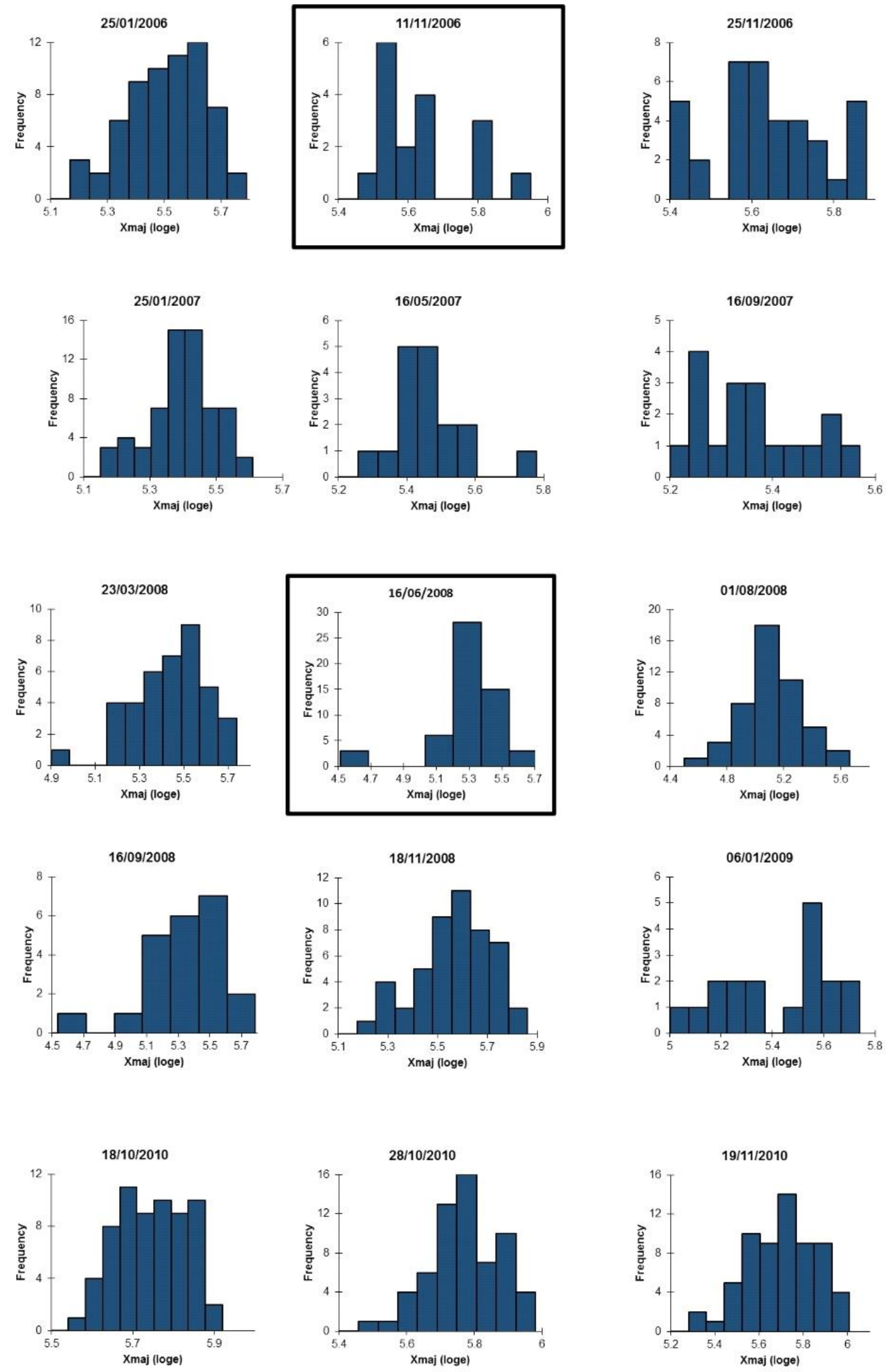

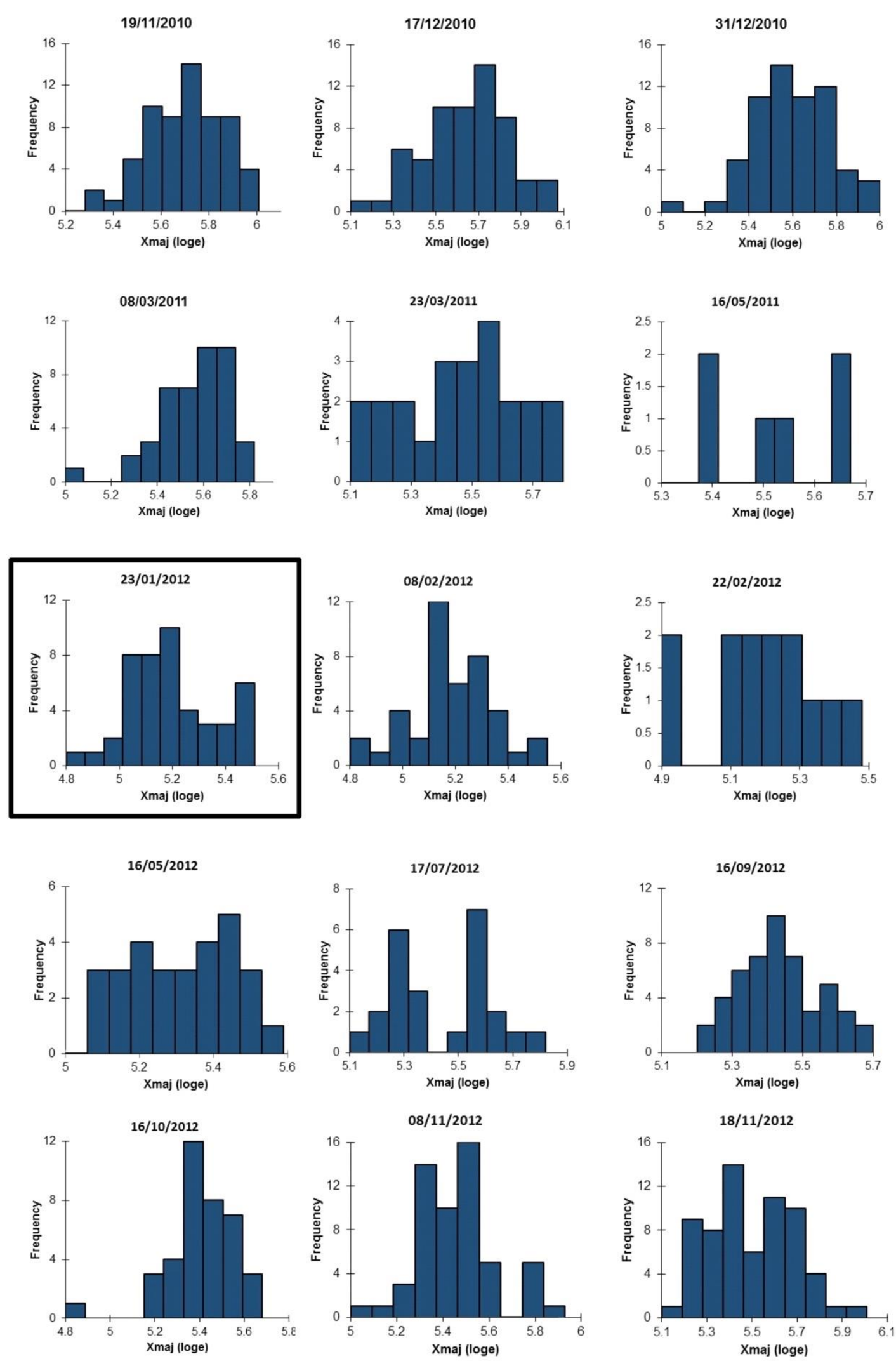

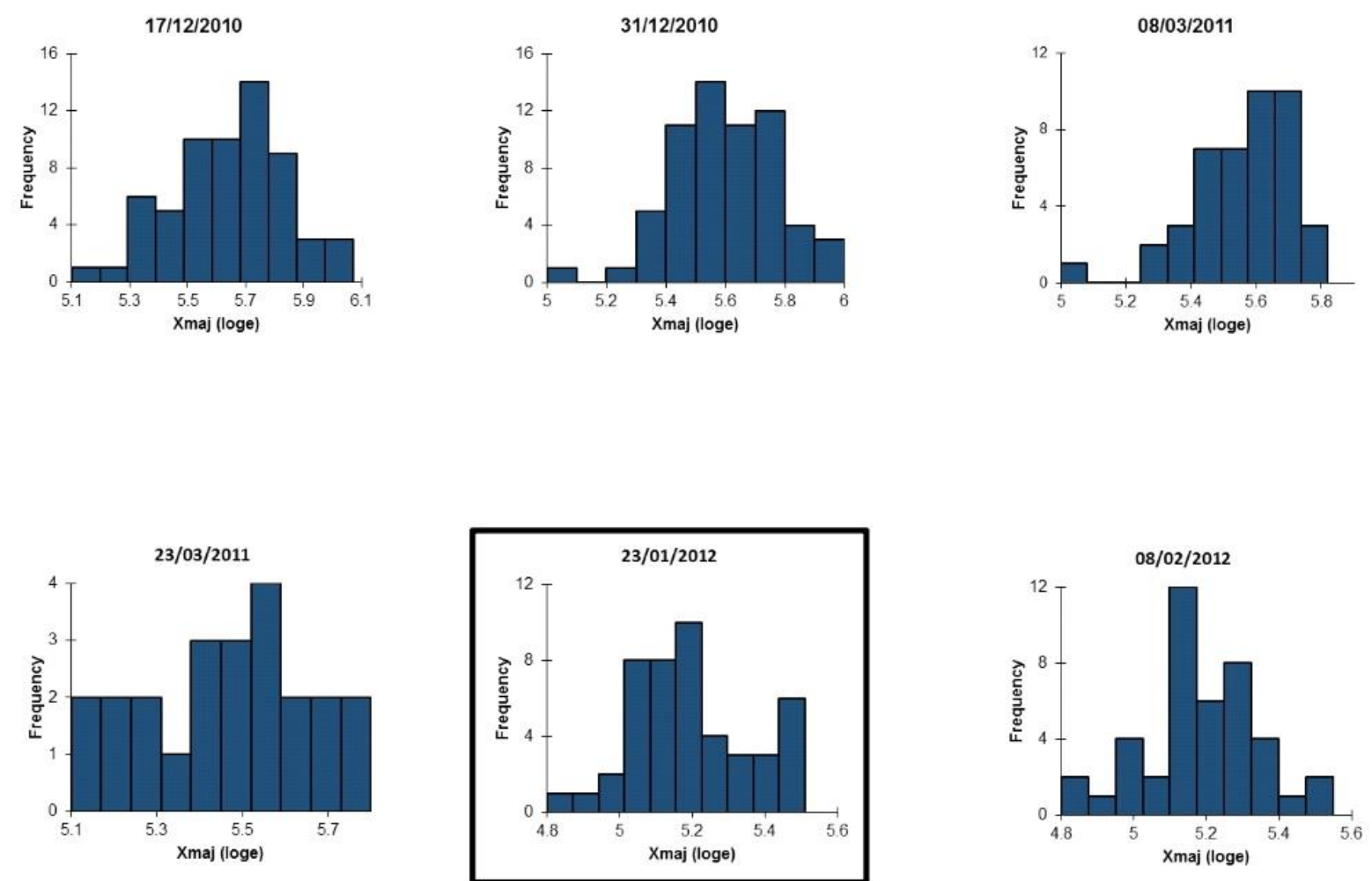

Figure S3: Histograms of the log-transformed maximum diameter values of each sample. Nonnormally distributed datasets are highlighted with black outline (Anderson-Darling Normality test; $\mathbf{p}<0.05)$. 


\section{Results of Principal Component Analyses of morphometric data}

The distributions of the four size-invariant morphological parameters (circularity ratio, box ratio, elongation ratio and compactness coefficient, Table S2), which relate to test shape, were analysed within each sample (manually collected dataset) using principal component analysis (PCA) (representative sample shown in main text). The presence of multiple clusters and thus multiple growth stages can also be supported by undertaking Anderson-Darling test for normality on the first principle component site scores. Fourteen of the 32 samples display a non-normal distribution (Table S3) indicating that in those 14 samples both pre-adult and adult specimens are likely present. To assess the relationship between the test size and the test shape the log-transformed maximum diameter of each specimen was plotted against the first principal component scores (for example, see main text). The two parameters correlated with each other in 12 of the 32 samples (Table S3) (four samples were discounted from the total of 36 samples due to the number of specimens being less than 15, see main text; Figure S4). The linear correlation coefficients ( $\mathrm{r}$ values) were between -0.48 and 0.51 , which suggests variable relationship between shape and size, i.e. positive correlation - as a specimen becomes larger it also becomes more rounded or in the case of negative correlations the specimens were more rounded the smaller they were. The result from the largest sample is shown in Figure S5.

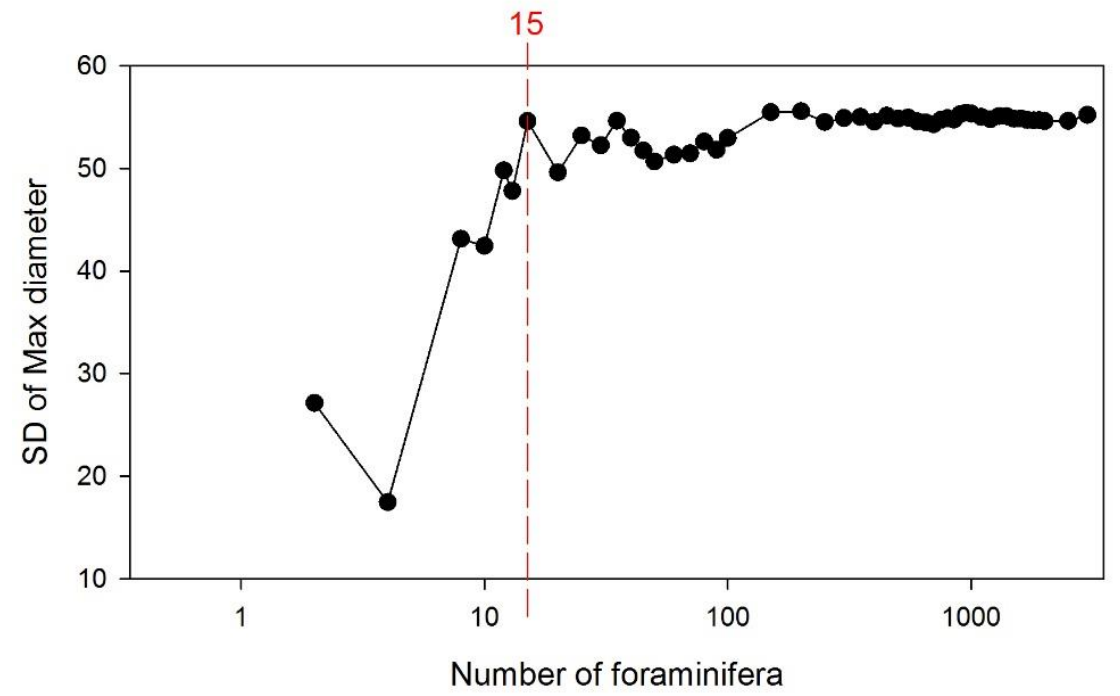

Figure S4: Rarefaction curve for maximum diameter, showing standard deviation of measurements versus foraminiferal count number.

Table S2: Definition of secondary morphological parameters, which relate to test shape as opposed to test size are derived from measured parameters (Moller et al. 2013).

\begin{tabular}{|c|c|c|c|}
\hline \multicolumn{2}{|c|}{ Primary parameters } & \multicolumn{2}{c|}{ Secondary morphological parameters } \\
\hline $\mathrm{p}$ & Perimeter & $\mathrm{Rc}=\mathrm{A} * 4 * \pi / \mathrm{p} 2$ & Circularity ratio \\
\hline $\mathrm{A}$ & Area & $\mathrm{Re}=2 * \sqrt{\mathrm{A}} /(\mathrm{Xmax} * \sqrt{ } \pi)$ & Elongation ratio \\
\hline $\mathrm{Xmax}$ & Maximum diameter & $\mathrm{B}=\mathrm{Xmin} / \mathrm{Xmax}$ & Box ratio \\
\hline $\mathrm{Xmin}$ & Minimum diameter & $\mathrm{C}=\mathrm{p} / 2 * \sqrt{ } * \sqrt{\mathrm{A}}$ & Compactness coefficient \\
\hline
\end{tabular}


Table S3: Mid-date of collection period for sediment trap samples, number of data points per sample, Anderson-Darling $p$ value of significance of the $1^{\text {st }}$ principal component scores (f1) of the PCA conducted on the normalised size-invariant morphological dataset, and the correlation coefficient, $r$, calculated between the log-transformed maximum diameter (Xmaj) and F1.

Significant values are highlighted in bold.

\begin{tabular}{|c|c|c|c|}
\hline Date & Count & $\begin{array}{r}\text { Anderson-Darling } \\
\text { p value }\end{array}$ & $\begin{array}{r}\text { Xmaj(ln)-Size- } \\
\text { invariant PCA F1 r } \\
\text { value }\end{array}$ \\
\hline $25 / 01 / 2006$ & 62 & 0.225 & -0.118 \\
\hline 11/11/2006 & 17 & 0.517 & -0.110 \\
\hline $25 / 11 / 2006$ & 38 & 0.503 & -0.213 \\
\hline 25/01/2007 & 63 & 0.203 & 0.043 \\
\hline $16 / 05 / 2007$ & 17 & 0.308 & -0.083 \\
\hline $16 / 09 / 2007$ & 18 & 0.045 & -0.035 \\
\hline $23 / 03 / 2008$ & 39 & 0.358 & -0.216 \\
\hline $16 / 06 / 2008$ & 55 & 0.030 & -0.338 \\
\hline 01/08/2008 & 48 & 0.001 & 0.442 \\
\hline $16 / 09 / 2008$ & 22 & 0.373 & 0.081 \\
\hline $18 / 11 / 2008$ & 49 & 0.390 & 0.037 \\
\hline 06/01/2009 & 18 & 0.114 & 0.262 \\
\hline 18/10/2010 & 64 & 0.527 & -0.480 \\
\hline 28/10/2010 & 63 & 0.009 & -0.324 \\
\hline 19/11/2010 & 63 & 0.009 & 0.323 \\
\hline $17 / 12 / 2010$ & 62 & 0.054 & -0.025 \\
\hline $31 / 12 / 2010$ & 62 & 0.029 & 0.248 \\
\hline 08/03/2011 & 43 & $<0.0001$ & 0.124 \\
\hline $23 / 03 / 2011$ & 23 & 0.180 & 0.508 \\
\hline 23/01/2012 & 46 & 0.000 & 0.046 \\
\hline 08/02/2012 & 42 & 0.016 & -0.214 \\
\hline $16 / 05 / 2012$ & 29 & 0.297 & 0.480 \\
\hline $17 / 07 / 2012$ & 24 & 0.006 & 0.136 \\
\hline $16 / 09 / 2012$ & 49 & 0.000 & -0.033 \\
\hline $16 / 10 / 2012$ & 38 & 0.103 & 0.010 \\
\hline 08/11/2012 & 56 & 0.051 & -0.291 \\
\hline 18/11/2012 & 65 & $<0.0001$ & -0.431 \\
\hline $02 / 12 / 2012$ & 64 & 0.151 & -0.351 \\
\hline 09/12/2012 & 50 & 0.539 & -0.353 \\
\hline 23/12/2012 & 50 & 0.051 & -0.148 \\
\hline $30 / 12 / 2012$ & 64 & 0.011 & -0.235 \\
\hline 27/01/2013 & 61 & 0.004 & -0.389 \\
\hline
\end{tabular}




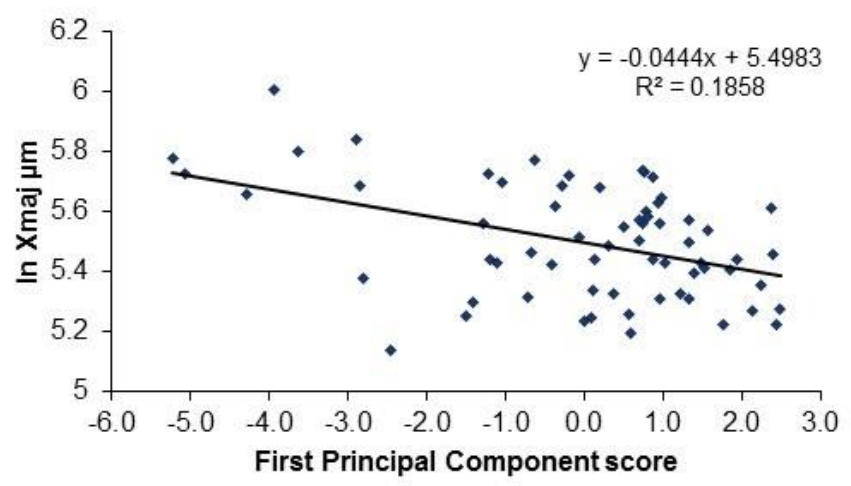

Figure S5: Relationship between the log-transformed maximum diameter (ln Xmaj) and the $1^{\text {st }}$ principal component scores of the PCA conducted on the normalised size-invariant morphological values. Figure shown is from 18/11/2012, which contains the largest number of specimens analysed. 
To assess the relationship between the shape and the size parameters in each set of samples, PCA was performed on the mean values of the log-transformed maximum diameter and the mean values of each size-invariant morphological parameter of the 36 sets of data (Figure S6, Table S4). Three principal components explain $99.9 \%$ of the variability in the dataset. The first principal component (F1) is strongly correlated with the size-invariant variables (Table S4). It increases with increasing circularity, elongation and box ratio and increases with decreasing compactness coefficient. This suggests that these four criteria covary. F1 can therefore be viewed as a measure of circularity ratio, elongation ratio, box ratio, and compactness coefficient. F1 correlates most strongly with elongation ratio and box ratio with correlation coefficients of 0.819 and 0.792 (Table S4) indicating that the first principal component is primarily a measure of these two variables and the observed variability in the dataset is related to changes in elongation in two dimensions, i.e. how elongate or round the specimens are, which relates to the ratio between the minor axis and major axis. The second principal component (F2) is also correlated with circularity ratio, elongation ratio, box ratio, and compactness coefficient, but to a lesser degree. Strongest correlation is recorded between circularity ratio and F2 (-0.641) (Table S4), so this component (F2) can be viewed as a measure of how close to a perfect sphere the specimens are. The third principal component (Figure S7 - F1-F3 biplot) only makes up $17 \%$ of the total variability in the dataset in comparison to the $49 \%$ and $33 \%$ of contribution of $\mathrm{F} 1$ and $\mathrm{F} 2$, respectively. However, it does show a strong positive correlation with maximum diameter $(\mathrm{r}=$ 0.840 , Table S4 Xmaj) suggesting that this component is a measure of specimen size. The biplot of the PCA results reveal these strong correlations between the principal components and the variables. PCA biplots are used mainly to determine groupings of observations based on the positions of the variables with respect to the principle components. In Figure S7 the observations are scattered across both F1 and F2 and that observations which belong to the same seasons do not cluster together.

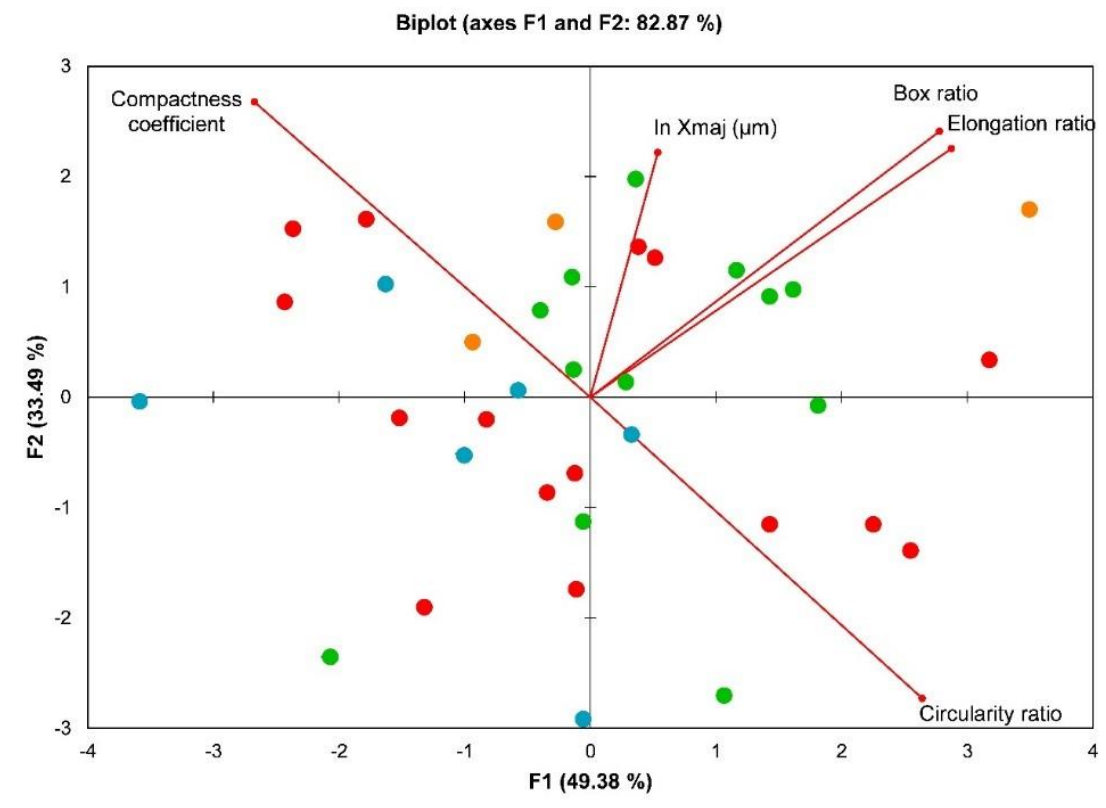

Figure S6: PCA biplot (F1-F2 scores) of the mean values of log-transformed maximum diameter and the mean values of each size-invariant morphological parameter covering the time series. Seasons are identified as: green $=$ spring, red $=$ summer, orange $=$ autumn, and blue $=$ winter .

The dataset used for the PCA analysis was separated out based on the presence/absence of correlation between log-transformed MD and first principal component scores of PCA on size-invariant 
morphological parameters within a given sample. Two PCAs were carried out on the datasets separated by the presence/absence of correlation between log-transformed maximum diameter and F1 of the PCA conducted on the normalised size-invariant morphological dataset (Table S2). These showed similar results to the PCA that was carried out on the dataset which was not separated by the correlation (Figure S8, Table S4). Neither PCA show any clear clustering of points based on seasonal separation of the data (Figure S8). Differences arise when the impact of the morphological variables is considered on the principle components. In the dataset where no correlation exits between the log-transformed MD and the first principal component scores of PCA on size-invariant morphological parameters $99 \%$ of the variability can be explained by three principal components (Figure S8) which is similar to the results of the PCA analysis conducted on the entire dataset together (Figure S7). Correlation between the morphological variables and the principal components (Figure S8) is also similar to the relationships identified in the PCA of the data from the 32 sediment trap samples (Figure S7): F1 and F2 correlate strongly with size-invariant variables, F3 with log-transformed maximum diameter, but the directions of the correlations are the opposite. In Figure S7 (dataset where samples show no relationship between shape and size) F1 is most strongly correlated with compactness coefficient and circularity ratio $(r=0.867$ and -0.864 respectively), suggesting that it is a measure of how compact and perfectly spherical a specimen is. F2 shows similarly strong correlations with elongation ratio and box ratio $(r=0.817$ and 0.837$)$, therefore we can consider F2 to be a measure of how elongated a specimen is in two dimensions (box ratio is equal to the ratio between minimum diameter and maximum diameter). In the dataset where samples show a significant relationship between shape and size the first two principal components can explain over $90 \%$ of the variability. Here F1 is strongly correlated with the size-invariant variables and F2 with the log-transformed maximum diameter (Figure S8). Similarly to the results of the PCA conducted on the entire dataset prior to splitting it up (Figure S6) F1 is most strongly correlated with elongation ratio and box ratio ( $\mathrm{r}=0.941$ and 0.939 , respectively), therefore it can be considered to be a measure of these two variables. F2 is a measure of specimen size as it is only correlated with logtransformed maximum diameter $(\mathrm{r}=0.83)$. Hence, based on these findings, the results of the PCA conducted on the original dataset of 36 observations is highly influenced by the samples where a statistically significant relationship exists between the log-transformed MD (indicative of specimen size) and the size-invariant morphological parameters (indicative of shape). The lack of clustering into groups in any of the PCA biplots indicates that the observed morphological variability is related to a combination of environmental parameters acting on the wellbeing of the foraminifera (see main text for discussion). 
Table S4: Eigenvalues and correlation between variables and principal component factors of the PCA of the mean values of log-transformed maximum diameter and the mean values of each size invariant morphological parameters of the times series.

\begin{tabular}{l|rrr} 
Eigenvalues & \multicolumn{3}{c}{} \\
\hline & F1 & F2 & F3 \\
\hline Eigenvalue & 2.469 & 1.675 & 0.852 \\
Variability (\%) & 49.381 & 33.493 & 17.031 \\
Cumulative \% & 49.381 & 82.874 & 99.905 \\
Correlations between variables and & & & \\
factors & & & \\
\hline & F1 & F2 & F3 \\
\hline Circularity ratio & 0.753 & -0.641 & 0.147 \\
Elongation ratio & 0.819 & 0.529 & -0.220 \\
Box ratio & 0.792 & 0.565 & -0.227 \\
Compactness coefficient & -0.762 & 0.628 & -0.157 \\
$\ln$ Xmaj $(\mu \mathrm{m})$ & 0.153 & 0.521 & 0.840
\end{tabular}

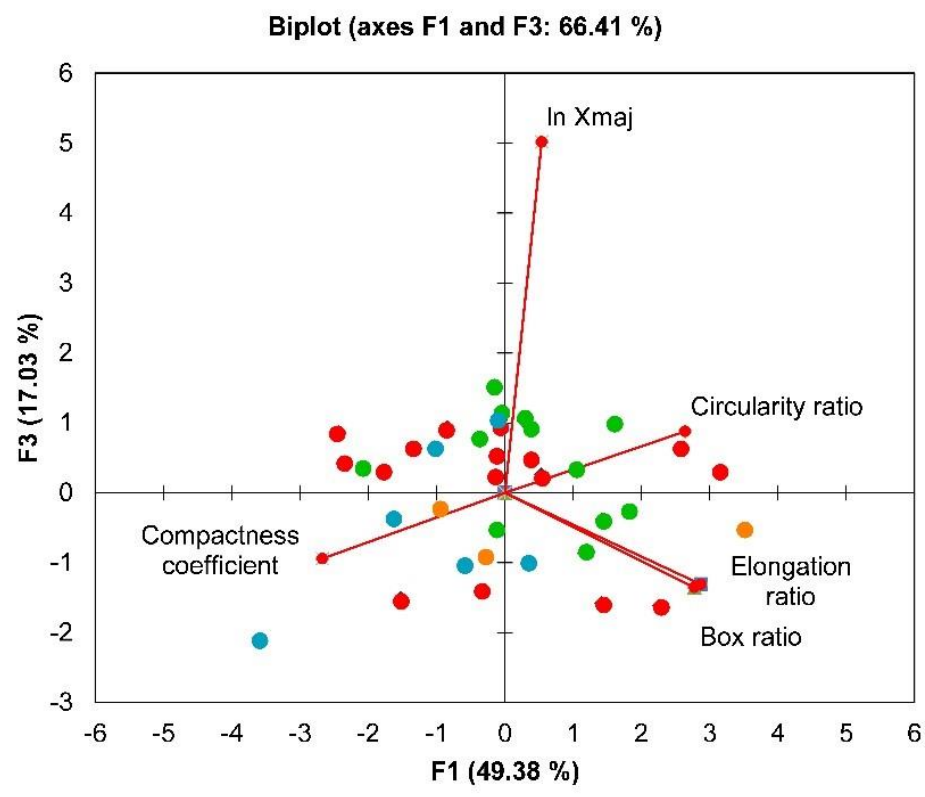

Figure S7: PCA biplot (F1-F3 scores) of the mean values of the log-transformed maximum diameter and the mean values of each size invariant morphological parameters covering the time series. Seasons are identified as: green $=$ spring, red $=$ summer, orange $=$ autumn, and blue = winter. 

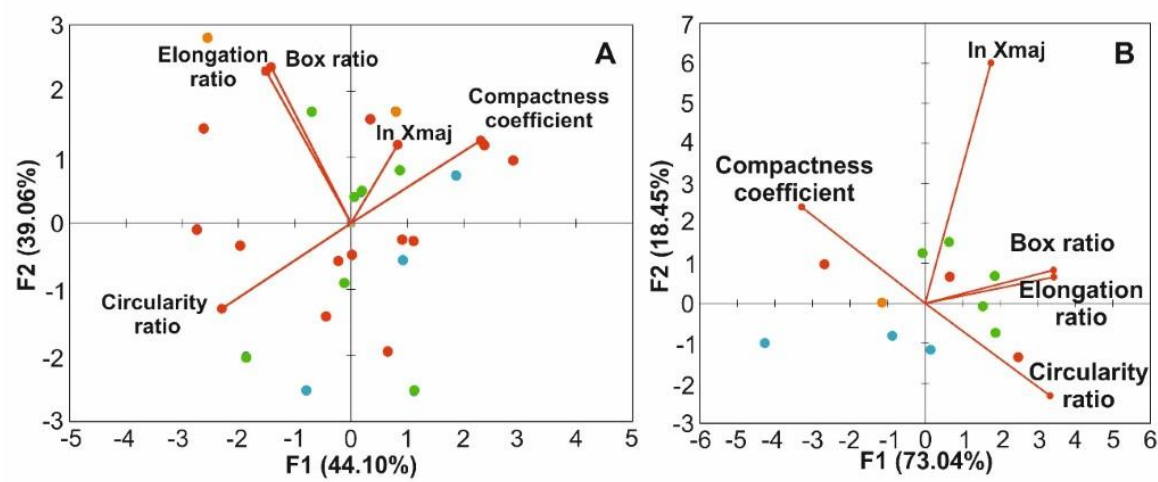

Figure S8: PCA biplots of the mean values of the log-transformed maximum diameter and the mean values of each size invariant morphological parameters belonging to samples where no correlation was found in Table S2.

Seasons are identified as: green $=$ spring, red $=$ summer, orange $=$ autumn, and blue $=$ winter .

To summarise the findings of this section:

- $\quad$ Statistical analysis supports the use of log-transformed maximum diameter as a measure of Nps size in a population (Figure S3).

- Inter-and intra-annual variability of Nps size is supported by statistical analysis.

- $\quad$ Specimens of different life stages are identified in 14 out of 32 samples by PCA.

- $\quad$ Positive and negative linear correlation between test shape and test size is found in 12 out of 32 samples.

- $\quad$ PCA revealed that size-invariant morphological parameters, particularly elongation and box ratio exert the greatest influence on test shape.

- $\quad$ The results of the PCA conducted on the entire dataset (36 samples) are strongly influenced by samples where statistically significant correlation exists between test shape and test size.

- $\quad$ The PCA analyses revealed no clustering of data points related to the seasons the samples derive from suggesting that the morphological variability is the result of a combination of variable environmental parameters (food availability, temperature, sea ice, etc). 
4. Comparing automated and manual morphometric data

\begin{tabular}{|c|c|c|c|c|c|c|c|c|}
\hline & \multicolumn{4}{|c|}{ Manual } & \multicolumn{4}{|c|}{ Automated } \\
\hline Date & Mean $(\mu \mathrm{m})$ & Median $(\mu \mathrm{m})$ & Var raw & Var norm & Mean $(\mu \mathrm{m})$ & Median $(\mu \mathrm{m})$ & Var raw & Var norm \\
\hline $25 / 01 / 2006$ & 251.63 & 253.36 & 1152.93 & 0.05 & 242.85 & 238.05 & 1541.67 & 0.04 \\
\hline 11/11/2006 & 290.64 & 272.57 & 1835.35 & 0.08 & 285.75 & 270.42 & 1805.99 & 0.09 \\
\hline $25 / 11 / 2006$ & 288.75 & 281.48 & 1515.67 & 0.07 & 286.58 & 285.37 & 2100.71 & 0.05 \\
\hline 25/01/2007 & 223.92 & 225.61 & 489.66 & 0.06 & 224.95 & 224.05 & 964.89 & 0.03 \\
\hline $16 / 05 / 2007$ & 240.69 & 235.14 & 957.73 & 0.05 & 245.29 & 236.17 & 1714.28 & 0.06 \\
\hline $16 / 09 / 2007$ & 218.25 & 213.40 & 599.00 & 0.08 & 221.13 & 218.19 & 612.34 & 0.08 \\
\hline $23 / 03 / 2008$ & 239.07 & 243.71 & 1636.13 & 0.05 & 245.37 & 248.06 & 1564.34 & 0.07 \\
\hline $16 / 06 / 2008$ & 208.47 & 211.41 & 1240.61 & 0.04 & 219.94 & 219.05 & 508.88 & 0.03 \\
\hline $01 / 08 / 2008$ & 171.43 & 163.96 & 1362.80 & 0.04 & 191.84 & 173.30 & 2194.57 & 0.09 \\
\hline $16 / 09 / 2008$ & 216.13 & 224.63 & 2221.53 & 0.06 & 219.01 & 221.72 & 1252.07 & 0.08 \\
\hline $18 / 11 / 2008$ & 269.11 & 269.59 & 1590.50 & 0.06 & 267.17 & 269.08 & 2121.51 & 0.06 \\
\hline $09 / 12 / 2008$ & 279.05 & 289.86 & 2283.97 & 0.10 & 254.59 & 253.51 & 2787.79 & 0.09 \\
\hline $06 / 01 / 2009$ & 236.89 & 249.42 & 2304.50 & 0.09 & 241.45 & 242.84 & 2236.07 & 0.11 \\
\hline $18 / 10 / 2010$ & 321.23 & 320.59 & 742.37 & 0.06 & 324.87 & 323.30 & 762.93 & 0.05 \\
\hline $28 / 10 / 2010$ & 325.30 & 330.48 & 2304.83 & 0.02 & 331.74 & 330.23 & 1067.02 & 0.05 \\
\hline 19/11/2010 & 311.54 & 315.42 & 2412.81 & 0.05 & 300.04 & 302.07 & 2862.93 & 0.03 \\
\hline $17 / 12 / 2010$ & 292.87 & 293.88 & 3399.50 & 0.05 & 292.19 & 293.84 & 3424.12 & 0.03 \\
\hline $31 / 12 / 2010$ & 278.19 & 275.30 & 2598.75 & 0.04 & 306.81 & 304.27 & 2979.67 & 0.05 \\
\hline $08 / 03 / 2011$ & 268.92 & 274.49 & 1433.41 & 0.04 & 279.68 & 291.78 & 2385.11 & 0.05 \\
\hline $23 / 03 / 2011$ & 244.94 & 242.41 & 2253.77 & 0.08 & 244.75 & 241.80 & 2272.19 & 0.05 \\
\hline $16 / 05 / 2012$ & 209.99 & 211.63 & 943.57 & 0.07 & 200.13 & 209.25 & 1043.83 & 0.07 \\
\hline $17 / 07 / 2012$ & 237.31 & 233.02 & 1908.04 & 0.07 & 211.63 & 200.34 & 1637.21 & 0.09 \\
\hline $16 / 09 / 2012$ & 236.63 & 232.94 & 778.09 & 0.06 & 235.02 & 230.11 & 921.67 & 0.04 \\
\hline $08 / 11 / 2012$ & 243.38 & 241.30 & 2012.95 & 0.04 & 250.25 & 247.47 & 2139.62 & 0.04 \\
\hline 18/11/2012 & 254.27 & 242.52 & 2376.29 & 0.04 & 265.64 & 255.16 & 2948.18 & 0.04 \\
\hline $02 / 12 / 2012$ & 279.29 & 280.43 & 4263.58 & 0.02 & 281.13 & 270.95 & 3841.31 & 0.03 \\
\hline $09 / 12 / 2012$ & 289.16 & 296.09 & 4267.76 & 0.05 & 244.23 & 241.77 & 1101.26 & 0.07 \\
\hline 23/12/2012 & 278.20 & 264.38 & 3363.44 & 0.07 & 253.77 & 241.88 & 2968.27 & 0.06 \\
\hline $30 / 12 / 2012$ & 281.02 & 284.35 & 3872.97 & 0.05 & 275.53 & 271.03 & 2643.69 & 0.04 \\
\hline 27/01/2013 & 257.70 & 262.00 & 1821.63 & 0.06 & 254.90 & 256.43 & 2575.27 & 0.03 \\
\hline
\end{tabular}

Table S5 (over page): Comparison of the sample mean, medians, and variances $\left(\sigma^{2}\right)$ of raw and normalised maximum diameter dataset measured by the manual and automated method. By normalising the maximum diameter $\left(X_{\max }\right)$ values $\left(X_{\text {max }, n}=\left(n-n_{\text {min }}\right) /\left(n_{\text {max }}-n_{\text {min }}\right)\right.$ it is possible to reduce the large range in the between sample variance (Moller et al., 2013). 


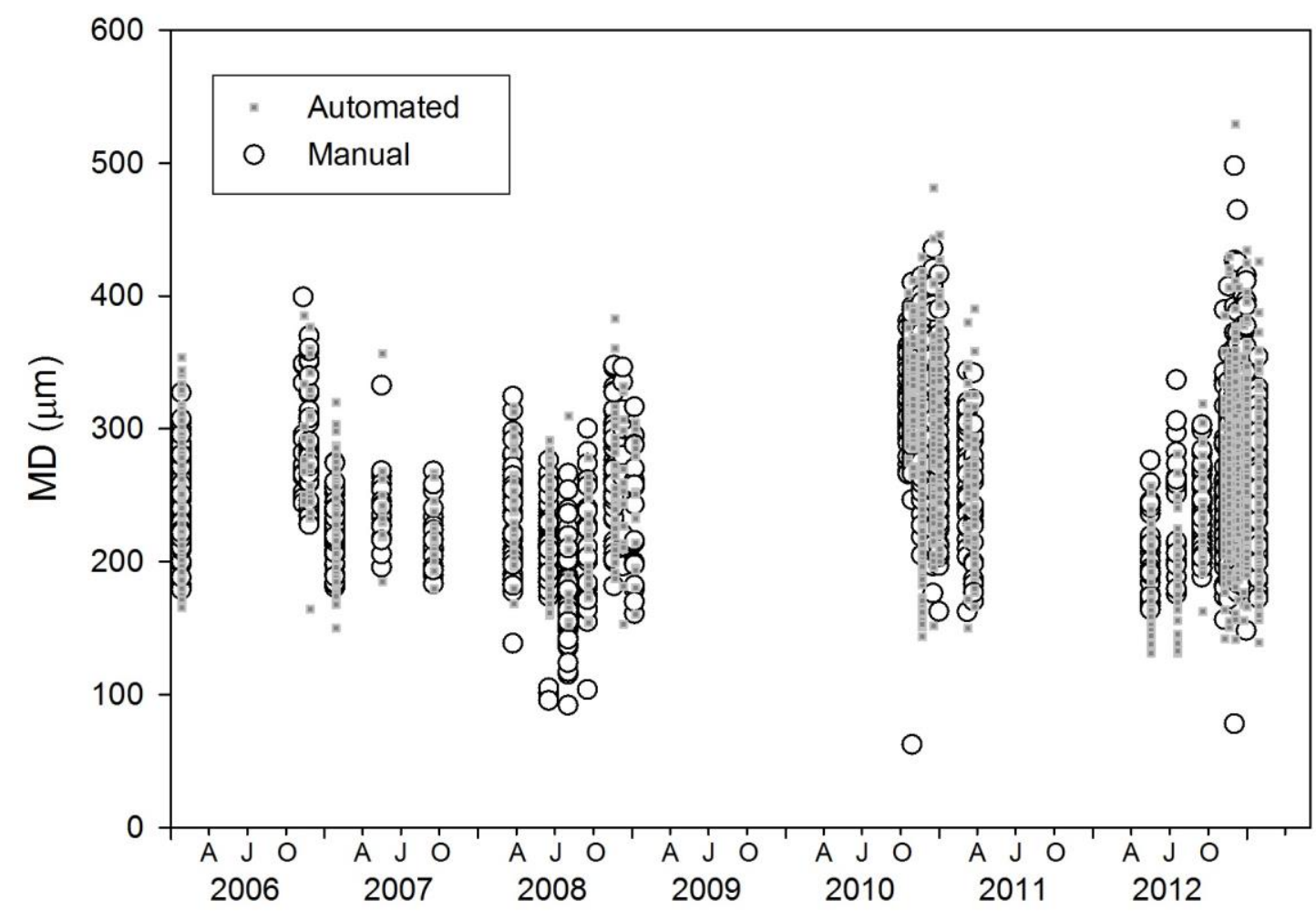

Figure S9: Plot of all automated and manual data collected from sediment trap foraminifera. AJO: April (autumn), July (winter), October (spring). 

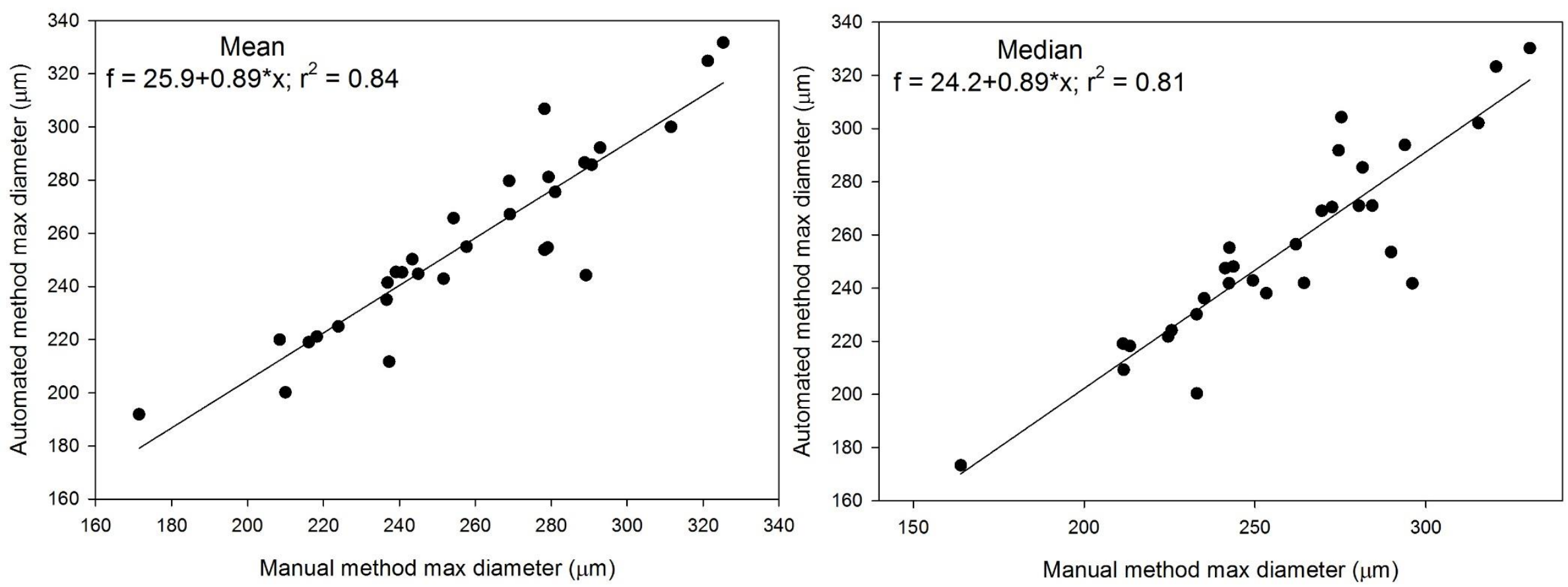

Figure S10: Correlation between the two methods, comparing (left) means of maximum diameters from each method and (right) medians. Linear regression equations and $\mathbf{r}^{2}$ values given in each case. 
Table S6: Results of Mann-Whitney U-tests (p values) and number of data points. Statistically significant $(p<0.05)$ results are highlighted in bold

\begin{tabular}{|c|c|c|c|}
\hline Date & $\mathrm{p}$ & n (Manual) & $\begin{array}{l}\mathrm{n} \\
\text { (Automated) }\end{array}$ \\
\hline $25 / 01 / 2006$ & 0.048 & 62 & 435 \\
\hline 11/11/2006 & 0.851 & 17 & 11 \\
\hline $25 / 11 / 2006$ & 0.922 & 38 & 28 \\
\hline $25 / 01 / 2007$ & 0.914 & 63 & 129 \\
\hline $16 / 05 / 2007$ & 0.740 & 17 & 12 \\
\hline $16 / 09 / 2007$ & 0.704 & 18 & 15 \\
\hline $23 / 03 / 2008$ & 0.530 & 39 & 35 \\
\hline $16 / 06 / 2008$ & 0.016 & 55 & 313 \\
\hline 01/08/2008 & 0.141 & 48 & 10 \\
\hline $16 / 09 / 2008$ & 0.974 & 22 & 24 \\
\hline $18 / 11 / 2008$ & 0.793 & 49 & 36 \\
\hline $09 / 12 / 2008$ & 0.191 & 12 & 17 \\
\hline 06/01/2009 & 0.864 & 18 & 14 \\
\hline 18/10/2010 & 0.557 & 64 & 62 \\
\hline 28/10/2010 & 0.663 & 63 & 57 \\
\hline $19 / 11 / 2010$ & 0.162 & 63 & 471 \\
\hline $17 / 12 / 2010$ & 0.894 & 62 & 96 \\
\hline $31 / 12 / 2010$ & 0.001 & 62 & 103 \\
\hline 08/03/2011 & 0.169 & 43 & 38 \\
\hline 23/03/2011 & 0.917 & 23 & 48 \\
\hline $16 / 05 / 2012$ & 0.347 & 29 & 23 \\
\hline 17/07/2012 & 0.122 & 24 & 11 \\
\hline $16 / 09 / 2012$ & 0.716 & 49 & 52 \\
\hline 08/11/2012 & 0.246 & 56 & 59 \\
\hline 18/11/2012 & 0.192 & 65 & 110 \\
\hline $02 / 12 / 2012$ & 0.903 & 64 & 108 \\
\hline 09/12/2012 & $<0.001$ & 50 & 35 \\
\hline 23/12/2012 & 0.028 & 50 & 59 \\
\hline $30 / 12 / 2012$ & 0.482 & 64 & 136 \\
\hline $27 / 01 / 2013$ & 0.576 & 61 & 155 \\
\hline
\end{tabular}


Table S7: Correlation ( $r$ ) and slope of regression values between maximum diameter and surface area measurements (manual data collection method) 32 samples of the time series (four samples with less than 15 specimens/sample were removed, see main text). Number of specimens in each sample and the $r$ value at $95 \%$ statistical significance are also included in table.

\begin{tabular}{l|rrrr} 
Date & Correlation & $\begin{array}{r}\text { r value at 0.05 } \\
\text { significance }\end{array}$ & Count & $\begin{array}{r}\text { Slope of } \\
\text { regression }\end{array}$ \\
\hline $\mathbf{2 5 / 0 1 / 2 0 0 6}$ & 0.980 & 0.250 & 62 & 0.804 \\
$\mathbf{1 1 / 1 1 / 2 0 0 6}$ & 0.969 & 0.456 & 17 & 0.855 \\
$\mathbf{2 5 / 1 1 / 2 0 0 6}$ & 0.982 & 0.304 & 38 & 0.819 \\
$\mathbf{2 5 / 0 1 / 2 0 0 7}$ & 0.969 & 0.250 & 63 & 0.852 \\
$\mathbf{1 6 / 0 5 / 2 0 0 7}$ & 0.968 & 0.456 & 17 & 0.877 \\
$\mathbf{1 6 / 0 9 / 2 0 0 7}$ & 0.959 & 0.444 & 18 & 0.816 \\
$\mathbf{2 3 / 0 3 / 2 0 0 8}$ & 0.988 & 0.304 & 39 & 0.86 \\
$\mathbf{1 6 / 0 6 / 2 0 0 8}$ & 0.987 & 0.273 & 55 & 0.791 \\
$\mathbf{0 1 / 0 8 / 2 0 0 8}$ & 0.988 & 0.288 & 48 & 0.868 \\
$\mathbf{1 6 / 0 9 / 2 0 0 8}$ & 0.994 & 0.400 & 22 & 0.833 \\
$\mathbf{1 8 / 1 1 / 2 0 0 8}$ & 0.977 & 0.273 & 49 & 0.833 \\
$\mathbf{0 6 / 0 1 / 2 0 0 9}$ & 0.991 & 0.444 & 18 & 0.85 \\
$\mathbf{1 8 / 1 0 / 2 0 1 0}$ & 0.981 & 0.250 & 64 & 0.803 \\
$\mathbf{2 8 / 1 0 / 2 0 1 0}$ & 0.992 & 0.250 & 63 & 0.822 \\
$\mathbf{1 9 / 1 1 / 2 0 1 0}$ & 0.983 & 0.250 & 63 & 0.903 \\
$\mathbf{1 7 / 1 2 / 2 0 1 0}$ & 0.983 & 0.250 & 62 & 0.836 \\
$\mathbf{3 1 / 1 2 / 2 0 1 0}$ & 0.982 & 0.250 & 62 & 0.866 \\
$\mathbf{0 8 / 0 3 / 2 0 1 1}$ & 0.983 & 0.288 & 43 & 0.888 \\
$\mathbf{2 3 / 0 3 / 2 0 1 1}$ & 0.995 & 0.400 & 23 & 0.904 \\
$\mathbf{2 3 / 0 1 / 2 0 1 2}$ & 0.990 & 0.288 & 46 & 0.826 \\
$\mathbf{0 8 / 0 2 / 2 0 1 2}$ & 0.983 & 0.304 & 42 & 0.807 \\
$\mathbf{1 6 / 0 5 / 2 0 1 2}$ & 0.976 & 0.349 & 29 & 0.915 \\
$\mathbf{1 7 / 0 7 / 2 0 1 2}$ & 0.990 & 0.381 & 24 & 0.828 \\
$\mathbf{1 6 / 0 9 / 2 0 1 2}$ & 0.968 & 0.273 & 49 & 0.852 \\
$\mathbf{1 6 / 1 0 / 2 0 1 2}$ & 0.980 & 0.304 & 38 & 0.863 \\
$\mathbf{0 8 / 1 1 / 2 0 1 2}$ & 0.979 & 0.250 & 56 & 0.778 \\
$\mathbf{1 8 / 1 1 / 2 0 1 2}$ & 0.985 & 0.250 & 65 & 0.76 \\
$\mathbf{0 2 / 1 2 / 2 0 1 2}$ & 0.984 & 0.250 & 64 & 0.772 \\
$\mathbf{0 9 / 1 2 / 2 0 1 2}$ & 0.986 & 0.273 & 50 & 0.78 \\
$\mathbf{2 3 / 1 2 / 2 0 1 2}$ & 0.985 & 0.273 & 50 & 0.807 \\
$\mathbf{3 0 / 1 2 / 2 0 1 2}$ & 0.989 & 0.250 & 64 & 0.819 \\
$\mathbf{2 7 / 0 1 / 2 0 1 3}$ & 0.974 & 0.250 & 61 & 0.766 \\
& & & &
\end{tabular}


Table S8: Spearman's correlation coefficient $(r)$ values. Statistically significant $(p<0.05)$ results are highlighted in bold. See cross-plots in figure S9.

\begin{tabular}{l|l|l|l|l|l|l} 
Variable & Nps flux & $\begin{array}{l}\text { Carbon } \\
\text { flux }\end{array}$ & $\begin{array}{l}\text { Nitrogen } \\
\text { flux }\end{array}$ & $\begin{array}{l}\text { Sea-Ice } \\
\text { Conc. }\end{array}$ & SST & Chlorophyll $a$ conc. \\
\hline Nps flux & $\mathbf{1}$ & $\mathbf{0 . 2 2 9}$ & $\mathbf{0 . 2 1 9}$ & -0.035 & 0.112 & -0.005 \\
Carbon flux & $\mathbf{0 . 2 2 9}$ & $\mathbf{1}$ & $\mathbf{0 . 9 8 9}$ & $\mathbf{- 0 . 4 9 3}$ & $\mathbf{0 . 7 9 0}$ & $\mathbf{0 . 3 1 2}$ \\
Nitrogen flux & $\mathbf{0 . 2 1 9}$ & $\mathbf{0 . 9 8 9}$ & $\mathbf{1}$ & $\mathbf{- 0 . 4 8 0}$ & $\mathbf{0 . 7 7 0}$ & $\mathbf{0 . 3 0 9}$ \\
Sea Ice Conc. & -0.035 & $\mathbf{- 0 . 4 9 3}$ & $\mathbf{- 0 . 4 8 0}$ & $\mathbf{1}$ & $\mathbf{- 0 . 6 1 0}$ & 0.160 \\
SST & 0.112 & $\mathbf{0 . 7 9 0}$ & $\mathbf{0 . 7 7 0}$ & $\mathbf{- 0 . 6 1 0}$ & $\mathbf{1}$ & 0.077 \\
Chlorophyll a conc. & -0.005 & $\mathbf{0 . 3 1 2}$ & $\mathbf{0 . 3 0 9}$ & 0.160 & 0.077 & $\mathbf{1}$
\end{tabular}



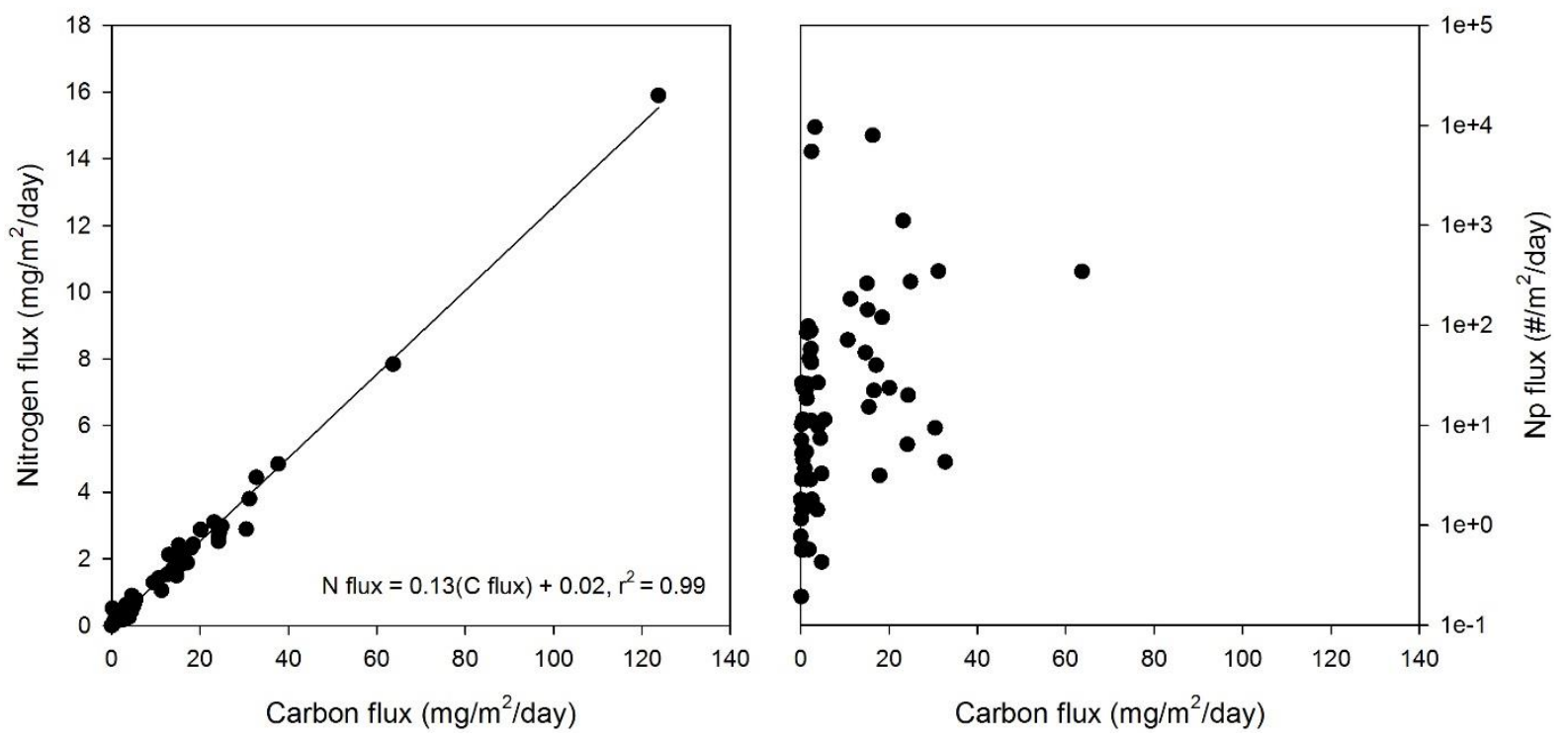

Figure S11: Cross-plots of carbon flux in sediment traps and (left) nitrogen flux and (right) foraminiferal flux. 
5. Relative frequency plots of stable isotope data
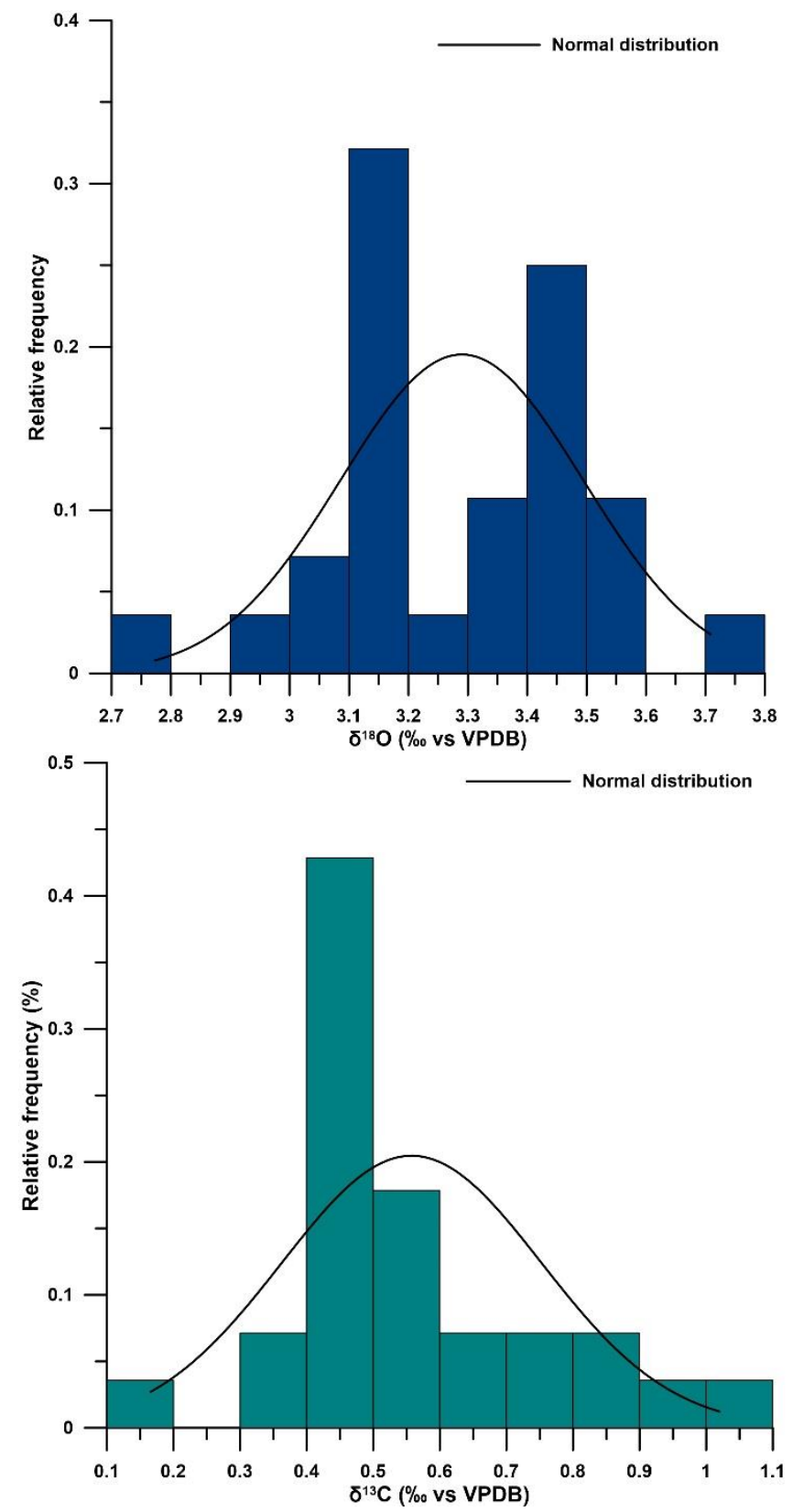

Figure S12: Relative frequency histogram of bulk (top) $\delta^{18} \mathrm{O}_{\mathrm{np}}$ and (bottom) $\delta^{13} \mathrm{C}_{\mathrm{np}}$. Black line represents the expected normal distribution. Anderson-Darling test for normality (results as $p$ values) revealed a normal distribution for $\delta^{18} \mathrm{O}_{\mathrm{np}}$ and non-normal distribution for $\delta^{13} \mathrm{C}_{\mathrm{np}}$. 


\section{Calculated seawater oxygen isotope profiles}

To compensate for the lack of year-round $\delta^{18} \mathrm{O}_{\mathrm{sw}}$ data WOA13 salinity (Zweng et al., 2013) data were used to calculate expected $\delta^{18} \mathrm{O}_{\mathrm{sw}}$ values for the period between January and October using Equation A:

$\delta^{18} \mathrm{O}_{\mathrm{sw}}=0.3387 \times \mathrm{S}-11.796$

where $\mathrm{S}$ is salinity (Meredith et al., 2017). An alternative $\delta^{18} \mathrm{O}_{\mathrm{sw}}$ equation (Equation $\mathrm{B}$ ) was used to calculate $\delta^{18} \mathrm{O}_{\mathrm{sw}}$ for the period between October and December due to the introduction of glacial and sea ice melt into the surface water during the spring. Only surface values $(0-50 \mathrm{~m})$ were calculated for the October-December period as only surface water $(0-50 \mathrm{~m}) \delta^{18} \mathrm{O}_{\mathrm{sw}}$ measurements exist for this period.

$\delta^{18} \mathrm{O}_{\mathrm{sw}}=0.0458 \times \mathrm{S}-1.8883$

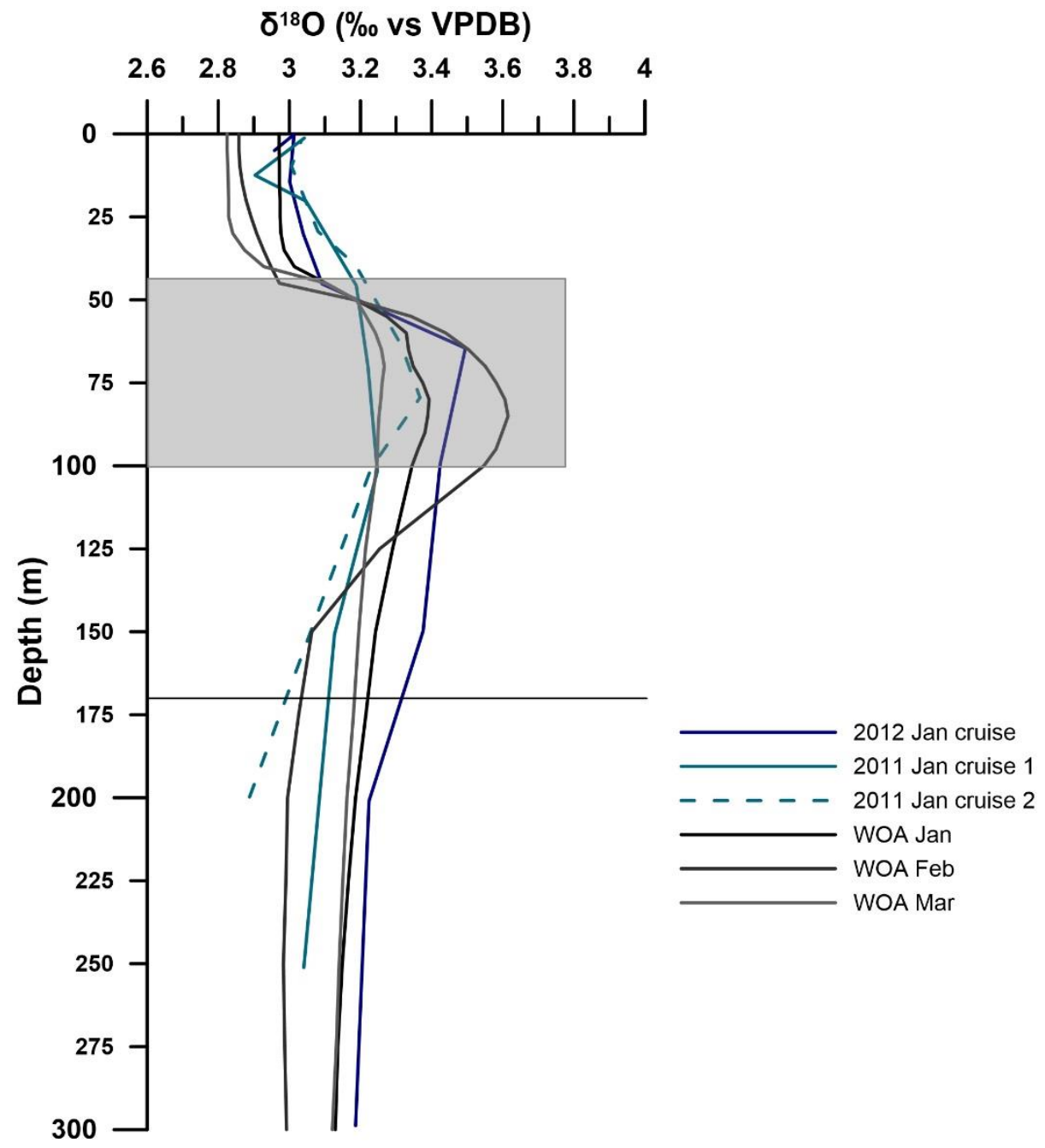

Figure S13: $\delta^{18} \mathrm{O}_{\text {eq }}$ depth profiles calculated from direct $\delta^{18} \mathrm{O}_{\text {sw }}$ observations from Meredith et al. (2016; blue) and from calculated $\delta^{18} \mathrm{O}_{\text {sw }}$ data based on WOA13 salinity measurements (grey). 
7. Link between stable isotopic composition and size in N. pachyderma
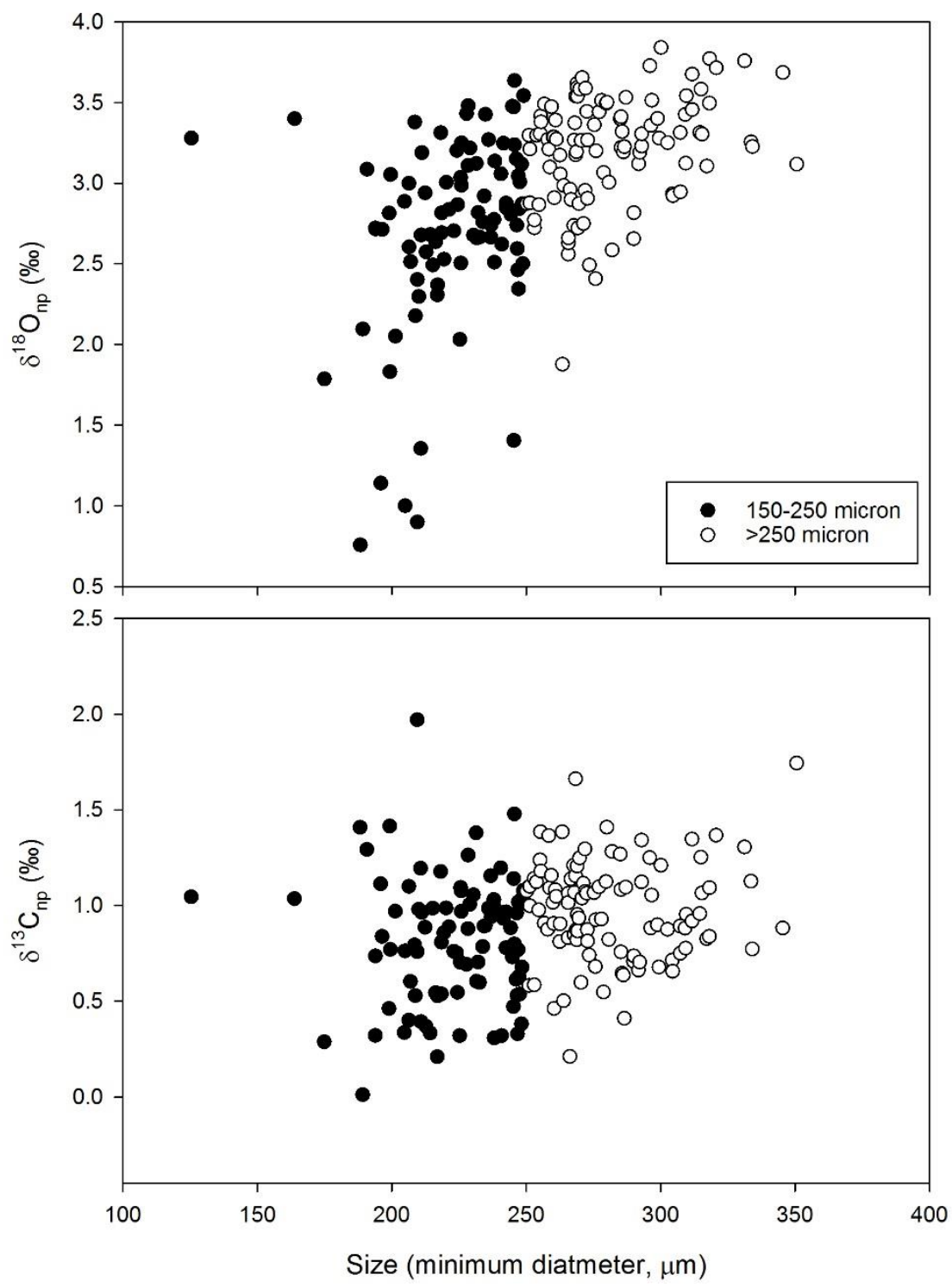

Figure S14: Cross plots of $N$. pachyderma shell size (minimum diameter) and isotopic composition. See main text for correlation statistics. 